\title{
A theory evaluation of an induction programme
}

\author{
Authors: \\ Kenrick Hendricks ${ }^{1}$ \\ Joha Louw-Potgieter ${ }^{1}$ \\ Affiliations: \\ ${ }^{1}$ Section of Organisational \\ Psychology, University of \\ Cape Town, South Africa \\ Correspondence to: \\ Joha Louw-Potgieter \\ Email: \\ joha.louw-potgieter@uct. \\ ac.za

\section{Postal address:} \\ Section of Organisational \\ Psychology, University of \\ Cape Town, Rondebosch \\ 7701, South Africa \\ Dates: \\ Received: 05 Oct. 2011 \\ Accepted: 30 Jan. 2012 \\ Published: 13 July 2012 \\ How to cite this article: \\ Hendricks, K., \& Louw- \\ Potgieter, J. (2012). A \\ theory evaluation of an \\ induction programme. $S A$ \\ Journal of Human Resource \\ Management/SA Tydskrif vir \\ Menslikehulpbronbestuur, \\ 10(3), Art. \#421, 9 pages. \\ http://dx.doi.org/10.4102/ \\ sajhrm.v10i3.421
}

(C) 2012. The Authors

Licensee: AOSIS

OpenJournals. This work

is licensed under the

Creative Commons

Attribution License.
Orientation: An induction programme is commonly used to help new employees understand their job within the organisation.

Research purpose: The main aim of this study was to examine whether or not the programme theory of an induction programme was plausible and would lead to the intended outcomes as described by the programme manager.

Motivation for the study: Induction training is one of the most common training programmes in an organisation. However, there is little research to evaluate whether or not the activities of an induction programme will lead to the intended outcomes of such a programme.

Research design, approach and method: This theory evaluation used a descriptive design. One hundred and thirteen employees of a media company completed a ten-item, five-point Likert scale which measured their perceptions of the programme's outcome, identification with the organisation and intentions to stay with the organisation.

Main findings: From this theory evaluation it was apparent that an induction programme based on an implausible programme theory could be problematic. An implausible programme theory affects the design of the programme activities and unsuitable activities may not deliver the desired outcomes.

Practical/managerial implications: The intention of the evaluation is to guide human resource managers through a process of replacing an implausible programme theory with one that is plausible, and which ensures better alignment of programme activities and outcomes.

Contribution/value-add: The evaluators showed how a plausible programme theory could improve programme design. This redesigned induction programme may lead to benefits, such as staff retention and company identification, rather than the vague assumption that it has been conforming to a legal obligation.

\section{Introduction}

This study aimed to evaluate whether or not an induction programme, designed for a media company, was based on a plausible programme theory and whether the programme activities were aligned with this theory or not.

Induction training is one of the most common types of organisational training programmes (Klein \& Weaver, 2000). Prior research suggests that most organisations implement some form of induction to help new employees familiarise themselves with their jobs (Wesson \& Gogus, 2005). When reviewing the literature on induction programmes, one is struck by the fact that most of the literature appears in popular publications and that the benefits of such programmes are asserted but not empirically proven.

Induction (or on-boarding, as it is known in the United States of America [USA]), refers to the process of combining the people, processes and technology needed to optimise the effect that a new hire has on business outcomes (Snell, 2006). Induction programmes can either occur as formal training programmes, informal induction carried out by co-workers and supervisors or a combination of both (Klein \& Weaver, 2000). These programmes can also vary depending on the job level of the new employee and the variety of programme activities (Wesson \& Gogus, 2005). According to Mestre, Stainer and Stainer (1997), the main aim of induction is to lessen the fear or anxiety experienced by new employees regarding settling into a job or performance.

Several researchers have indicated the benefits of induction programmes. According to Butler (2008), Wells (2005) and Wesson and Gogus (2005) new employees are most vulnerable during the first few weeks of employment and poor induction significantly raises the risk of turnover 
in this group. Therefore, it is important that an organisation has a mechanism in place to capitalise on early optimism and imprint the employer's brand of how the organisation functions (Derven, 2008). Often the first one hundred days of a new employee's career are critical in determining whether he or she will assimilate into the organisation and thrive, or fail to do so (Fritz \& Vonderfecht, 2007).

According to Snell (2006), induction presents significant benefits to organisations such as a reduction in the amount of time it takes for new employees to adjust in an organisation (Ragsdale \& Mueller, 2005) and to reach full working capacity (Brodie, 2006; Derven, 2008).

Successful induction programmes can also lead to cost savings (Cooper-Thomas \& Anderson, 2006). The indirect costs of early departure of a newly hired executive (Wells, 2005) or labour turnover (Derven, 2008; Friedman, 2006) could be reduced by a good induction programme. On the other hand, the direct cost of an induction programme could be reduced by automating the process (Butler, 2008).

Induction programmes not only benefit organisations, they also offer significant benefits to employees. According to Derven (2008), induction reinforces a new employee's decision to join the organisation and fosters a feeling of belonging. A well-organised induction programme will aid staff in dealing with anxiety by providing them with coping strategies like goal setting and planning during one of the most stressful times in their organisational life (Wanous \& Reichers, 2000). By reducing insecurity and anxiety, induction programmes are able to help employees settle in faster and feel more at home in the organisation (Dodds \& Verest, 2002; Ragsdale \& Mueller, 2005). These positive emotions may lead to improved levels of satisfaction amongst new employees (Sussman, 2005), which in turn could translate into more productive workers who feel part of the organisation (D'Aurizio, 2007).

Customer satisfaction can be improved by sending new employees on an induction programme that is tailored to provide the necessary support to avoid demoralisation during the initial working period (D'Aurizio, 2007). Pollitt (2007) showed that customer-satisfaction ratings for new employees at a major UK energy provider doubled to $80 \%$ after introducing such an induction programme.

Induction programmes provide both tangible and cost-related benefits for an organisation as well as emotional benefits for its employees. Companies that can reduce the time taken to integrate new employees will gain a competitive advantage as employees will reach their full productivity sooner, have higher morale and will be more likely to remain in the same job (Moscato, 2005).

One could ask whether these benefits mentioned in the literature derive from specific programme activities or not. The literature on induction programme activities indicates that benefits can be categorised into content, process, support and follow-up (D'Aurizio, 2007; Wanous \& Reichers, 2000).

\section{Content}

Two kinds of information are required in an induction programme: firstly, general information about employees' work routines and secondly, a review of the organisation's history and mission and the way new employees would be expected to contribute to the latter (Mestre et al., 1997). This is supported by Snell (2006) and Wanous and Reichers (2000), who view the covering of health and safety procedures, a brief history of the new organisation, a tour of the building and introduction to co-workers as some of the essential aspects for creating an ideal induction programme. It is also recommended that induction programmes include elements that communicate benefits to new employees (e.g. employee assistance programmes [EAP], health plan options and discount programmes) (Butler, 2008).

According to Snell, (2006) an induction programme should contain an element relating to the organisation's information technology. This will typically involve the allotment of computer hardware and software along with basic guidelines for acceptable use of these resources (Hacker, 2004; Pudhan, 2002; Snell, 2006).

New employees need to be introduced to the organisational structure, culture, work standards and organisational expectations (Ragsdale \& Mueller, 2005). It is recommended that new employees meet all the individuals who will aid them in performing their job adequately (D'Azurizio, 2007) and are informed of their role and its contribution within the department (Hamilton, 2007). Manager-facilitated training, in which the organisational culture, values and the employee's job expectations are communicated, was suggested by Sussman (2005). A reception, in the form of a lunch or outing attended by direct managers and executive leadership, is often included as a social event in the programme (Hamilton, 2007).

\section{Process}

According to Wanous and Reichers (2000), 54\% of induction programmes are presented within the first month of employment. It is recommended that induction programmes have phased implementation (Derven, 2008), instead of the traditional one-off approach to programme implementation (Friedman, 2006). Ideally, these programmes take place after the first day of work and before the end of the first week, with activities spread over two to three hours each morning (Penzer, 1973). The length of an induction programme should vary between one and two weeks (D'Aurizio, 2007). The amount of time spent on induction-related procedures decreases with the passing of each month in the new job (Sussman, 2005). Butler (2008) recommends that an induction programme, containing information about direct reports, conditions of employment and required paperwork, should be delivered to new employees before their actual starting date. 
Ideally, no forms are handed out during the induction programme (Hamilton, 2007; Wanous \& Reichers, 2000) as such administrative tasks should be completed beforehand. It is recommended that all services, including work stations, email accounts and access to the relevant networks, should be set up before the new employee's start date (Butler, 2008). Following this, information related to the organisation's key markets, competitors, products and services could be communicated electronically to the new employee (Derven, 2008).

It is recommended that induction programmes consist of a blended learning curriculum that makes use of classroom instruction, frequent discussions with direct managers as well as self-guided e-learning (Sussman, 2005). Information that requires interpersonal interaction can be delivered in the classroom, whilst individualised job-related information is best presented electronically (Derven, 2008; Moscato, 2005; Ragsdale \& Mueller, 2005; Schneider, 2008). Managers should deliver information, regarding support and organisational resources available to the new employee, in person and as part of a process to create a good working relationship (Derven, 2008).

Penzer (1973) recommends that induction groups should be heterogeneous in job function but homogeneous in job level. This is because combining individuals of high and low job authority levels makes both groups uncomfortable. It is also recommended that new managers receive their own personalised form of induction training because the managers' performance in their jobs affects employees throughout the entire organisation (Brodie, 2006). However, this approach may not be practical in all organisations.

Finally it is recommended that the tone of the induction process should be celebratory rather than propagandistic (Hacker, 2004). When films or videos are used to sell the organisation, this should be kept in mind.

\section{Support}

As part of the induction process, it is recommended that a competent mentor is selected to support the new employee (D'Aurizio, 2007) and to provide information regarding the key challenges of the job, the performance expectations associated with it, the history of how the job was created and the possible political dynamics associated with the job role.

In addition, it is recommended that new employees are provided with information regarding nearby housing, schools and social services (Butler, 2008; D'Aurizio, 2007). Ideal induction programmes provide contact details to the new employee's direct manager and department, and also inform co-workers of the date of the new employees' arrival, in order for them to create a positive and welcoming environment on this day (D'Aurizio, 2007).

There are some novel methods of ensuring that induction programmes provide adequate support. According to
Hartley (2004), some organisations refer to pre-loaded personal digital assistants (PDAs) to promote new employee integration. These PDAs contain key tasks to be undertaken by the new employee, key contact information and in some cases digital images of relevant co-workers. Such guides may also contain professional and personal information of co-workers, their length of tenure at the organisation, their previous job roles, communication preferences and outside interests (Johnson, 2006). A less costly method of providing key information could be to refer to compact disks with readonly-memory (CD-ROMs) containing important website links, digital images of co-workers and online quick-reference guides containing policies, procedures and company ethics principles (Hartley, 2004). These support methods should be supplemented by personal meetings with the new employee's direct manager, in order to develop action plans for delivering results during the initial period of employment and to clarify any outstanding queries (Johnson, 2006).

It is suggested that induction programmes foster employee integration through the establishment of employee social networks (Derven, 2008). This can be accomplished by using social networking software that enables employees to create profiles of their professional and personal lives as a means of engaging with fellow employees and their employer (HRfocus, 2007). When new employees discover that they share common interests with existing employees, they are often able to collaborate more effectively on professional, workrelated tasks (Johnson, 2005).

\section{Follow-up}

It is recommended that induction programmes contain sessions for follow-up and assess new employee progress beyond the first day of employment (Fritz \& Vonderfecht, 2007; Hamilton, 2007). Meetings could be held with the new employees at key milestones early in their organisational careers (D'Aurizio, 2007). It is advised that these meetings also take place informally in a social setting, as this encourages networking and constructive feedback in a nonthreatening environment.

The follow-up process allows managers to ascertain whether or not there are enough resources to allow for employee integration, whether or not there are any political obstacles to professional socialisation, whether or not mentor support is adequate and, lastly, what the new employee's training needs are (Friedman, 2006). Information gathered during such a follow-up process will enable programme improvement.

\section{Evaluation objectives}

According to Rossi, Lipsey and Freeman (2004) programme theory refers to the assumptions of how a programme achieves its desired outcomes. Bickman (1987, p. 5) describes programme theory as '... the construction of a plausible and sensible model of how a programme is supposed to work'. According to Weiss (1998) a programme theory helps the client to understand the programme design and to improve it. 
In the current study, the evaluators examined whether or not the programme theory of the induction under evaluation is plausible. In order to ascertain this, a comprehensive programme description was required. This description contains the programme activities (what happens on the programme) which were then presented as a modest programme theory. This programme theory (as supplied by the client) was then tested for its plausibility against the social science literature presented earlier.

The one-day (09h00-15h00) induction programme described here is set in a media and magazine production environment that is fast-paced and deadline-driven. The human resource (HR) manager provided the following programme description.

It is intended that all new employees attend the induction programme. However, because of the specific demands of this workplace, this is not always possible and longer-serving employees and new employees sometimes attend the same programme.

The programme, presented by an HR Officer, starts with an ice-breaking exercise which requires all new employees to give a brief description of themselves, some of their interests and the department in which they work. This is followed by a presentation covering the company history and some aspects of the organisation's culture. Then a series of presentations on the organisation's core divisions (administration, HR, travel, operations, information technology [IT] and despatch) is delivered. The IT presentation is intended to inform new employees of policies regarding internet and e-mail use.

A break from presentations is provided at midday with a lunch function in the company bar. Direct managers, of the programme recipients, along with the Managing Director (MD) are invited to attend. The HR manager described this as an important activity within the programme as it aims to provide an opportunity for wider socialisation across the organisation. Furthermore, the presence of the MD signals that new employees are regarded as important and that they are welcomed personally into the organisation.

After lunch all attendees are taken on a tour of the organisation's building, which includes a visit to despatch where employees are provided with guidelines for sending and receiving post. The induction day ends with a photographing session.

The programme activities and outcomes are presented in Figure 1.

According to the media company's HR manager, the induction programme, as described (see Figure 1), results in the company fulfilling its legal obligation as prescribed by 'South African labour law'. In Figure 2, this programme theory is presented in a diagram.

Whilst induction programmes are generally recognised as good practice, there is no obligation in South African labour law to induct employees. Moreover, in the literature review, it was indicated how recipients of an induction programme benefit from it and it was indicated that the two most important outcomes of an induction programme are identification with the employer and staff retention. A more plausible programme theory, based on the outcomes of induction programmes as specified in the literature, is presented in Figure 3.

Based on this information, the following evaluation questions will be explored:

Evaluation question 1: Did the human resource manager's programme theory work for the recipients? In other words, were they aware that the outcome of the induction programme was the fulfilment of a legal obligation?

Evaluation question 2: Would the original induction programme lead, by default, to identification with the

\begin{tabular}{|c|c|}
\hline Activities & Outcomes \\
\hline $\begin{array}{l}\text { 1. Welcome and history of } \\
\text { organisation }\end{array}$ & $\begin{array}{l}\text { Feel welcome and be } \\
\text { familiar with organisation }\end{array}$ \\
\hline 2. Delegates' introduction & $\begin{array}{l}\text { Able to identify other } \\
\text { delegates and their respective } \\
\text { departments }\end{array}$ \\
\hline 3. Department presentations & $\begin{array}{l}\text { Feel familiar with } \\
\text { department functions }\end{array}$ \\
\hline 4. Covering IT policy & $\begin{array}{l}\text { Are familiar with IT policy } \\
\text { and reduce IT violations }\end{array}$ \\
\hline $\begin{array}{l}\text { 5. Lunch with Managing } \\
\text { Director and attendees' } \\
\text { own managers }\end{array}$ & $\begin{array}{l}\text { Feel welcome and important } \\
\text { to the organisation }\end{array}$ \\
\hline $\begin{array}{l}\text { 6. Tour of organisation } \\
\text { premises }\end{array}$ & $\begin{array}{l}\text { Familiar with } \\
\text { organisation premises }\end{array}$ \\
\hline $\begin{array}{l}\text { 7. Photographs and signing } \\
\text { of attendance document }\end{array}$ & $\begin{array}{l}\text { Identification card and } \\
\text { acknowledgement of legal } \\
\text { compliance }\end{array}$ \\
\hline
\end{tabular}

IT, information technology.

FIGURE 1: The media company's action plan containing induction activities and their related outcomes.

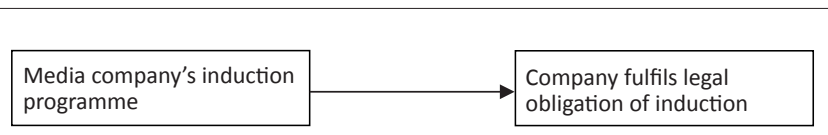

FIGURE 2: Media company's programme theory.

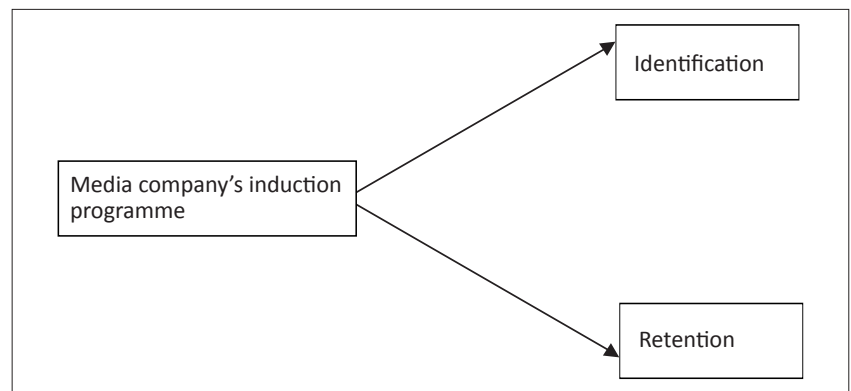

FIGURE 3: Programme theory based on social science literature. 
employer and staff retention? This evaluation question was included, as it was assumed that merely taking part in the programme activities might have unintended consequences, like identification and retention.

Evaluation question 3: If the original programme theory were changed (based on existing literature regarding induction programmes) would it lead to an improved design and, in the end, to a more effective programme?

The value of the current study lies in the causal links that are made explicit between the programme activities and the programme theory. These links answer the question: Will this programme deliver the intended outcomes or not?

\section{Research design \\ Research approach}

This theory evaluation used a descriptive design.

\section{Research method \\ Research participants}

At the time of the evaluation, there were 197 permanent and 14 fixed term contract employees in the company. A total of 113 employees attended the induction programme and completed the questionnaire. These participants to the programme included:

- 49 new employees who attended within their first month of employment

- 42 new employees who attended after one month

- 22 longer-serving employees who attended after two months or more of employment.

\section{Measuring instruments}

A ten-item, five-point Likert-type questionnaire was used to gather information from the programme participants. The questionnaire focused on the programme's outcome as specified by the programme manager (legal obligation) and other outcomes specified in the literature (organisational identification and staff retention). The questionnaire contained:

- three questions regarding perceptions that a legal obligation was fulfilled by the programme (these were devised by the evaluators)

- four questions on identification (adapted from Doosje, Ellemers \& Spears' [1995] Organisational Integration Scale)

- two questions on intention to stay (adapted from Cohen's [1993] Intention to Quit measure)

- a final question on the perceived usefulness of the induction programme for the participants.

The question items are presented in Table 1.

\section{Research procedure}

All 113 recipients of the induction programme completed the questionnaire electronically.

\section{Statistical analysis}

An exploratory factor analysis (EFA) was used to reduce the number of items in the questionnaire. Thereafter the number
TABLE 1: Induction programme questionnaire.

After attending the company's induction programme ...

1. I am aware of the company's rules and policies

2. I know what is required of me in my job

3. I know what my performance standards are

4. I see myself as a member of (the company)

5. I am pleased to be a member of (the company)

6. I feel strong ties with other members of (the company)

7. I identify with other members of (the company)

8. I am not looking for another job outside of (the company)

9. I think about remaining employed at (the company)

10. In general I found the induction programme useful

of factors was extracted using a principal components analysis. A one-way, between groups, analysis of variance was used to explore the impact of the length of tenure and the timing of induction attendance on the factors extracted.

\section{Ethical considerations}

The Ethics in Research Committee of the Faculty of Commerce, University of Cape Town, approved the evaluation.

\section{Potential benefits and hazards}

There were no benefits or hazards for participants who took part in the evaluation. The evaluators did not require that participants identify themselves and indicated that only number codes would be used for the questionnaire data.

\section{Recruitment procedures}

The primary evaluator sent the questionnaire electronically to all participants who had attended the induction programme.

\section{Informed consent}

On the first page of the questionnaire the purpose, confidentiality of the data and the time it would take to complete the questionnaire were described in detail.

\section{Data protection}

The webmaster, at the University of Cape Town, stripped each completed questionnaire of all identifiers and stored the data on a secure server. The primary evaluator was the only person who could access the data.

\section{Trustworthiness}

\section{Reliability}

The reliability of the questionnaire is described in the Results section.

\section{Validity}

The evaluation focused on a specific programme and did not seek to generalise the results to other, similar programmes.

\section{Results}

Cronbach's alpha $(\alpha=.837)$ indicated that the ten-item questionnaire had high internal reliability. 
An Exploratory Factor Analysis (EFA) was used to reduce the number of items in the questionnaire to those that best measure the constructs of Legal Obligation, Retention and Identification. In addition the EFA was used to detect the structure in relationships between these items (Pallant, 2007). All ten items of the questionnaire were included in the EFA.

The suitability of the data set for conducting an EFA was assessed. An initial inspection of the correlation matrix revealed the presence of several coefficients of .3 and above. This served as an early indicator of data suitability for factor analysis (Pallant, 2007). The Kaiser-Meyer-Oklin value was .74 , which exceeded the recommended value of .6 (Pallant, 2007), and Bartlett's Test of Sphericity reached statistical significance $(p=<.00)$, supporting the factorability of this specific correlation matrix.

The ten items in the questionnaire were then subjected to Principal Components Analysis (PCA) with Direct Oblimin extraction. Principal Components Analysis revealed the presence of three factors with eigen values exceeding 1 , which explained $41.9 \%, 15.9 \%$ and $12.3 \%$ of the $70.1 \%$ total variance respectively. An inspection of the pattern matrix revealed that two items were loading on more than one factor 'I see myself as a member of (the company); In general I found the induction programme useful'. In order to ensure that all of the items only load on one factor, the difference between the cross-loading items was examined. According to Pallant (2007), cross-loading items with a difference of less than .25 between them should be removed from an EFA. Using this guideline, the item, 'In general I found the induction programme useful', was removed from the EFA and three factors with no cross-loading items emerged (see Table 2).

In Table 2, the first three items (9, 8 and 5) loaded on a single factor, named Retention. Retention explained $42.3 \%$ of the variance. The second factor was named Identification and consisted of three items (4, 6 and 7). Identification explained $17.5 \%$ of the variance. The final factor consisted of three items $(3,2$ and 1) and was named Legal Obligation. This last factor explained $13.1 \%$ of the variance. The total variance explained by these three factors had increased to $73.0 \%$.

In order to answer evaluation question one, 'Does the HRM's programme theory work for the recipients?', and two, 'Would the original induction programme lead, by default,

TABLE 2: Pattern matrix after removing cross-loading item.

\begin{tabular}{lccc}
\hline Items & \multicolumn{3}{c}{ Component } \\
\cline { 2 - 4 } & $\mathbf{1}$ & $\mathbf{2}$ & $\mathbf{3}$ \\
\hline 9. I think about remaining employed at (the company) & .904 & .037 & -.074 \\
$\begin{array}{l}\text { 8. I am not looking for another job outside of } \\
\text { (the company) }\end{array}$ & .898 & -.097 & -.075 \\
7. I am pleased to be a member of (the company) & .754 & -.045 & .181 \\
6. I see myself as a member of (the company) & .629 & .327 & .125 \\
$\begin{array}{l}\text { 5. I feel strong ties with other members of } \\
\text { (the company) }\end{array}$ & .039 & .952 & -.042 \\
4. I identify with other members of (the company) & -.064 & .937 & .055 \\
3. I know what my performance standards are & -.044 & -.100 & .9253 \\
2. I know what is required of me in my job & -.022 & .042 & .821 \\
1. I am aware of the company's rules and policies & .102 & .098 & .554 \\
\hline
\end{tabular}

Extraction Method: Principal Component Analysis; Rotation Method: Oblimin with Kaiser Extraction Method
Normalisation.

Major loadings for each item are presented in bold. to identification with the employer and staff retention?', a one-way between groups analysis of variance (ANOVA) was conducted. This ANOVA explored the impact of the length of tenure and the timing of induction attendance on the levels of retention, identification and legal obligation. Programme participants were divided into three groups, according to their length of tenure and the timing of their induction programme attendance. These groups were:

- Group 1: New employees with first-month induction attendance.

- Group 2: New employees with induction attendance after one month of employment.

- Group 3: Long-serving employees with later induction attendance.

No statistically significant difference was found in the mean scores for the three groups at the $p<.05$ level in the questionnaire's Legal Obligation $(F=.289, p=.833)$, Retention $(F=1.234, p=.301)$ and Identification $(F=2.261, p=.085)$.

\section{Discussion}

The results will be discussed in terms of the main objectives of the study, namely the evaluation questions based on the programme theory. The discussion will highlight the importance of the causal links between programme activities and a plausible programme theory.

\section{Evaluation Question 1: Did the human resource manager's programme theory work for the recipients?}

From the results, it is clear that recipients of the induction programme did not experience it as a fulfilment of a legal obligation. If the company is ever challenged on whether or not it has fulfilled its legal obligation and programme recipients were asked to supply evidence of this, the recipients would most probably answer in the negative.

\section{Evaluation Question 2: Would the original induction programme lead, by default, to identification with the employer and staff retention?}

It was expected that the induction programme would not lead to company identification or employee retention, but questionnaire items were included to test that this did not happen simply because new employees spent time together on an induction programme. Therefore, the non-significant results pertaining to this evaluation question were not surprising.

\section{Evaluation Question 3: If the original programme theory were changed (based on existing literature regarding induction programmes) would it lead to an improved design and, in the end, to a more effective programme?}

From the results of evaluation questions 1 and 2, it was clear that the induction programme was not delivering 
the outcomes of 'legal obligation' or 'identification'. In the literature review the authors presented a number of studies detailing the typical programme activities of effective induction programmes implemented in other companies. In order to increase the usefulness of this evaluation report, an ideal induction programme was outlined, with company identification and staff retention as intended outcomes. It is suggested that the media company redesign its induction programme, based on these sound social science assumptions and empirical results. These ideal programme activities are presented in Figure 4.

These suggestions, for an improved induction programme, will be presented according to the four typical components that constitute an effective programme, namely content, support, follow-up and process (D'Aurizio, 2007).

\section{Content}

It is suggested that the programme starts with a welcoming element, followed by a review of the organisation's history and mission (Mestre et al., 1997), its organisational structure, culture and work standards (Ragsdale \& Mueller, 2005). Thereafter, employees could be made aware of the following:

- the organisation's expectations of them

- their work routines

- their contribution to the company's goals

- the people they should meet who would assist them to perform their jobs adequately (D'Aurizio, 2007).

Two other programme activities, relating to the employee's obligations regarding safety and IT use, could be included. It is recommended that the programme covers the organisation's unique health and safety procedures (Snell, 2006; Wanous \& Reichers, 2000) and acceptable use of computer hardware and software (Hacker, 2004; Snell, 2006). Both of these activities will address the legal obligation of the company to make employees aware of its safety and IT policies.

After all this information input, it is recommended that a reception be hosted for new employees with direct managers and executive leadership present (Hamilton, 2007). This social event may indicate that the organisation's leadership takes induction of new employees seriously.

\section{Process}

Unlike the current induction programme, where longerserving employees are required to attend, Wanous and Reichers (2000) suggest that an induction programme takes place within the first month of employment. The evaluators would like to suggest that the first induction meeting takes place within the first week rather than the first month of employment, as most employees in a fast-paced work environment might have acquired, by trial and error, relevant information about their jobs after the first month of work. It is also suggested that implementation of the programme be phased instead of being structured according to the current one-off presentation (Derven, 2008; Friedman, 2006). Programme activities can be spread over two to three hours

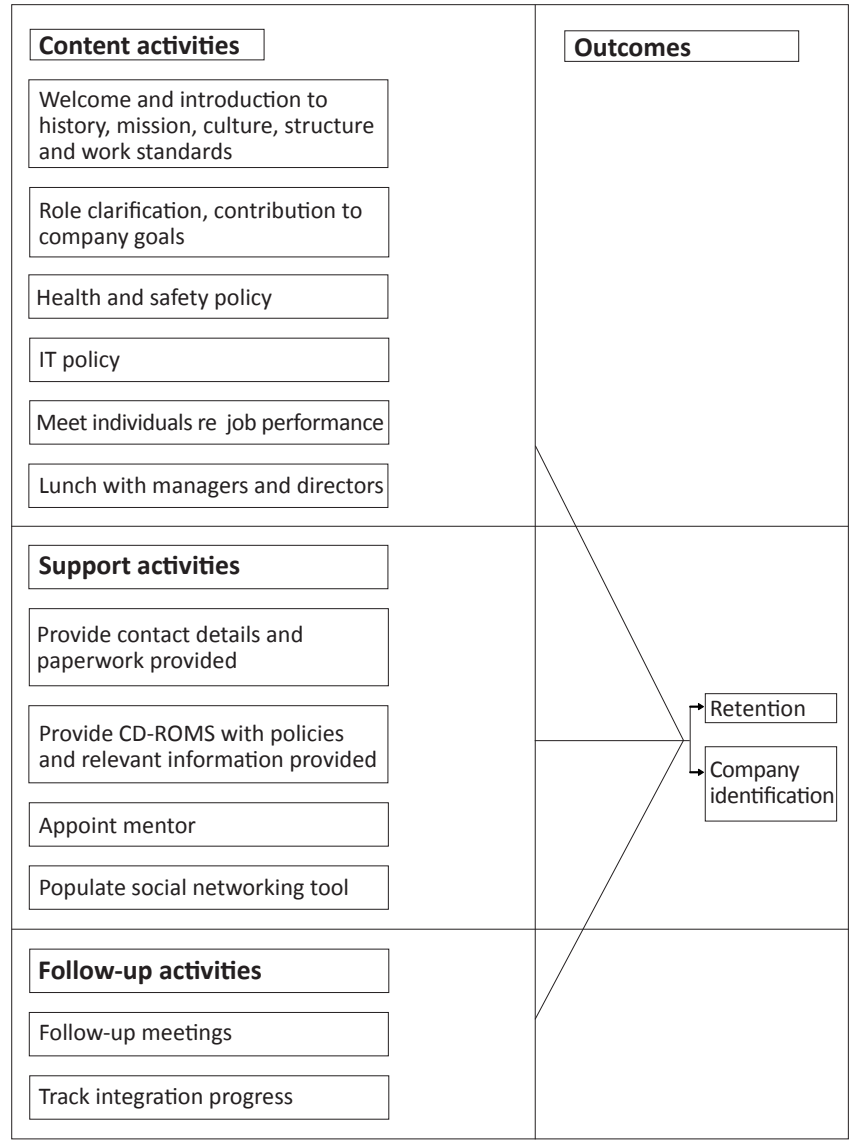

IT, information technology.

FIGURE 4: Ideal programme activities for induction programme.

each morning during the first week of employment (Penzer, 1973). This will allow the new employees to receive critical information in smaller and more manageable sessions, thus, making it easier for them to internalise and apply this information.

As employees are able to learn twice as fast through selfguided e-learning (Sussman, 2005), it is suggested that programme activities, which lend themselves to this medium (e.g. policies and procedures, company structure, personal education and training programmes, etc.), should be housed on the web for convenient all-day access (Schneider, 2008). Care should be exercised that these web-based interventions are supported by frequent discussions between new employees and their managers (Johnson, 2006) in order to determine integration progress and possible obstacles.

\section{Support}

Before the new employees start work, the contact details of their direct manager and co-workers and all relevant paperwork for completion could be supplied (Butler, 2008; D'Aurizio, 2007). These details, plus information about policies, procedures and company ethics (Hartley, 2004) could be presented to the new person on a compact disc. Coworkers and managers could be alerted to the employees' starting date in order to welcome them.

It is suggested that a competent, positive mentor (D'Aurizio, 2007) is selected to assist the new employees to gain job-related 
information from co-workers, clients and their manager (Johnson, 2006). The mentor could also play an important role in providing the new person with information regarding the cultural aspects of the organisation, namely what is regarded as important, which behaviours are rewarded or discouraged and inform them about the unspoken politics of the organisation.

Employee integration could be fostered by means of a social network tool which enables new employees to meet and interact with other employees with similar interests or jobs (Derven, 2008). New employees could, thus, create their personal profiles by means of this tool and communicate information regarding their professional and personal lives to other co-workers with the intention of further social interaction (HR-focus, 2007). Research indicates that when new employees discover shared interests with existing employees they find it easier to collaborate on professional work-related tasks (Johnson, 2005).

\section{Follow-up}

It is suggested that managers meet with new employees at key milestones early in their organisational careers in order to follow up and assess the progress of integration (D'Aurizio, 2007; Hamilton, 2007). These milestones may be time-bound (e.g. after one month, after three months, etc.) or they could be related to early performance (e.g. after the first deliverable is completed, and after the first client contact, etc.). These meetings should be informal, off site, in a social setting, as this encourages networking and constructive feedback in a non-threatening environment (D'Aurizio, 2007).

For programme improvement, it is suggested that the followup component should be structured in order to determine:

- whether or not there are enough resources available to allow for full employee integration

- whether or not mentor support is adequate

- whether or not there are any obstacles to professional socialisation

- and, most importantly, what the new employee's training and development needs are (Friedman, 2006).

\section{Conclusions}

From this theory evaluation it is apparent that an induction programme, based on an implausible programme theory, could be problematic. An implausible programme theory affects the design of the programme activities, and unsuitable activities may not deliver the desired outcomes. In this evaluation it has been shown how a plausible programme theory, based on sound social science principles, can improve programme design. This redesigned induction programme will ensure that the company reaps the benefits of staff retention and company identification rather than the vague assumption that it has been conforming to a 'legal obligation' as stated in this case.

\section{Suggestions for future research}

Should the media company implement the redesigned induction programme, it is suggested that an outcome evaluation is undertaken by it, in order to determine whether or not the new programme has, in fact, led to staff retention and company identification.

\section{Acknowledgements Competing interests}

The authors declare that they have no financial or personal relationship(s) which may have inappropriately influenced them in writing this paper.

\section{Authors' contributions}

K.H. (University of Cape Town) completed this evaluation as a requirement for his Master's degree in Programme Evaluation. J.L.-P. (University of Cape Town) supervised the evaluation.

\section{References}

Bickman, L. (1987). The functions of program theory. New Directions for Program Evaluation, 33, 5-18. http://dx.doi.org/10.1002/ev.1443

Brodie, J.M. (2006). Getting managers on board. Human Resources Magazine, November, 105-108.

Butler, K.M. (2008). Getting employees to stay onboard instead of jumping ship. Employee Benefit News, January, 13-14.

Cohen, A. (1993). Work commitment in relation to withdrawal intentions and union effectiveness. Journal of Business Research, 26, 75-90. http://dx.doi. org/10.1016/0148-2963(93)90044-P

Cooper-Thomas, H.D., \& Anderson, N. (2006). Organizational socialization. Journal of Managerial Psychology, 21, 492-516. http://dx.doi. org/10.1108/02683940610673997

D'Aurizio, P. (2007). Onboarding: Delivering on the promise. Journal of Nursing Economics, 25, 228-229.

Derven, M. (2008). Management onboarding. Journal of Training and Development, April, 49-52.

Dodds, B., \& Verest, M. (2002). E-learning in support of induction training at De Lage Landen. Journal of Industrial and Commercial Training, 34, 70-75. http://dx.doi. org/10.1108/00197850210417564

Doosje, B., Ellemers, N., \& Spears, R. (1995). Perceived intragroup variability as a function of group status and identification. Journal of Experimental Social Psychology, 31, 410-436. http://dx.doi.org/10.1006/jesp.1995.1018

Friedman, L. (2006). Are you losing potential new hires at hello? Journal of Training and Development, November, 25-27.

Fritz, L.R., \& Vonderfecht, D. (2007). The first 100 days. Journal of Healthcare Executive, November, 8-14.

Hacker, C.A. (2004). New employee orientation: Make it pay dividends for years to come. Journal of Information Systems Management, 89-92.

Hamilton, H. (2007). Onboarding secures talent for the long run. Journal of Workforce Management, 86, 1.

Hartley, D.E. (2004). Digital beat: Technology kicks up leadership development. Journal of Training and Development, March, 22-24.

HR-focus. (2007). Social networks: The newest employee engagement tool. HR focus News Briefs, November, 1.

Johnson, L.K. (2005). Get your new managers moving. Harvard Management Update, June, 3-5.

Johnson, L.K. (2006). Rapid onboarding at Capital One. Harvard Management Update, September, 3-4.

Klein, H.J., \& Weaver, N.A. (2000). The effectiveness of an organizational level orientation training program in the socialization of new hires. Journal of Personne Psychology, 53, 47-66. http://dx.doi.org/10.1111/j.1744-6570.2000.tb00193.x

Mestre, M., Stainer, A., \& Stainer, L. (1997). Employee orientation - the Japanese approach. Journal of Employee Relations, 19, 443-456. http://dx.doi. org/10.1108/01425459710186322

Moscato, D. (2005). Using technology to get employees onboard. Human Resources Magazine, April, 107-109. 
Pallant, J. (2007). SPSS: Survival manual. (3rd edn.). New York: McGraw Hill.

Penzer, W. (1973). Employee orientation: Does it relieve pain or create it? Management Review, 17-24.

Pollitt, D. (2007). Scottish and Southern Energy slashes staff attrition. Human Resource Management International Digest, 15, 17.

Pudhan, S. (2002). Secure networks begin at staff induction day. Computer Weekly, September, 1 .

Ragsdale, M.A., \& Mueller, J. (2005). Plan, do, study, act model to improve an orientation programme. Journal of Nursing Care Quality, 20, 268-272. http:// orientation programme. Journal of Nursing Care Quality, 20, $268-2$
dx.doi.org/10.1097/00001786-200507000-00013, PMid:15965393

Rossi, P., Lipsey, M.W., \& Freeman, H.E. (2004). Evaluation. A systematic approach. (7th edn.). Thousand Oaks: Sage.

Schneider, J.W. (2008). Building people, not just buildings. Journal of Building and Construction, March, 47-49.
Snell, A. (2006). Researching onboarding best practice. Strategic HR Review, 5, 32-35. http://dx.doi.org/10.1108/14754390680000925

Sussman, D. (2005). Getting up to speed. Journal of Training and Development, December, 49-51.

Wanous, J.P., \& Reichers, A.E. (2000). New employee orientation programs. Journal of Human Resource Management Review, 10, 435-451. http://dx.doi.org/10.1016/ S1053-4822(00)00035-8

Weiss, C.H. (1998). Evaluation: Methods for studying programs and policies. Upper Saddle River: Prentice Hall.

Wells, S.J. (2005). Diving in. Human Resources Magazine, March, 55-59.

Wesson, M.J., \& Gogus, C.I. (2005). Shaking hands with a computer: An examination of two methods of organizational newcomer orientation. Journal of Applied Psychology, 90(5), 1018-1026. http://dx.doi.org/10.1037/00219010.90.5.1018, PMid:16162074 